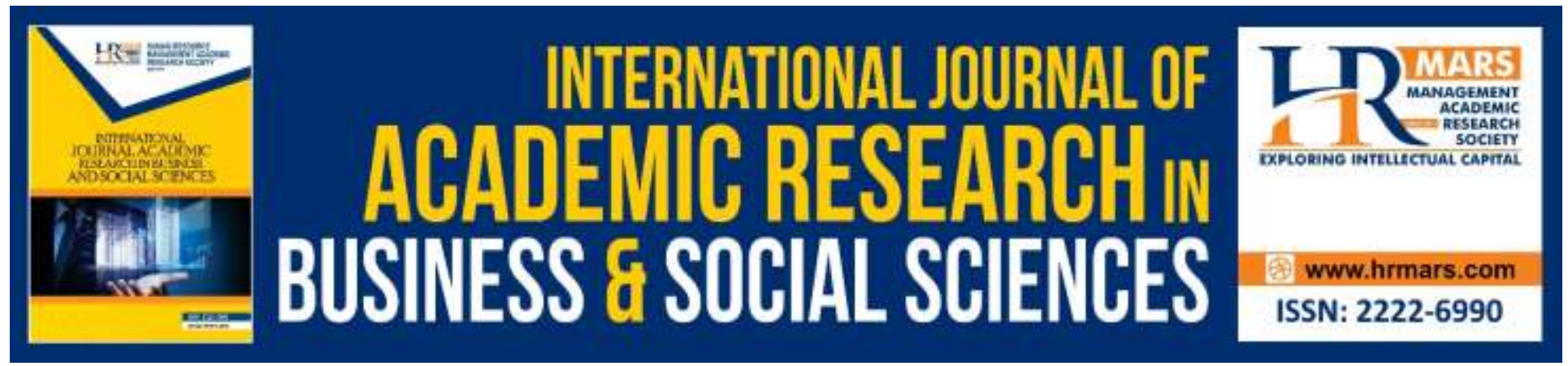

\title{
Perceptions of Social Media Use and Family values in the Northern Region of Ghana
}

\author{
Iliasu Adam
}

To Link this Article: http://dx.doi.org/10.6007/IJARBSS/v10-i1/6852

DOI:10.6007/IJARBSS/v10-i1/6852

Received: 22 December 2019, Revised: 10 January 2020, Accepted: 20 January 2020

Published Online: 29 January 2020

In-Text Citation: (Adam, 2020)

To Cite this Article: Adam, I. (2020). Perceptions of Social Media Use and Family values in the Northern Region of Ghana. International Journal of Academic Research in Business and Social Sciences, 10(1), 300-317.

\section{Copyright: (C) 2020 The Author(s)}

Published by Human Resource Management Academic Research Society (www.hrmars.com)

This article is published under the Creative Commons Attribution (CC BY 4.0) license. Anyone may reproduce, distribute, translate and create derivative works of this article (for both commercial and non-commercial purposes), subject to full attribution to the original publication and authors. The full terms of this license may be seen

at: http://creativecommons.org/licences/by/4.0/legalcode

Vol. 10, No. 1, 2020, Pg. 300 - 317

http://hrmars.com/index.php/pages/detail/IJARBSS

JOURNAL HOMEPAGE

Full Terms \& Conditions of access and use can be found at http://hrmars.com/index.php/pages/detail/publication-ethics 


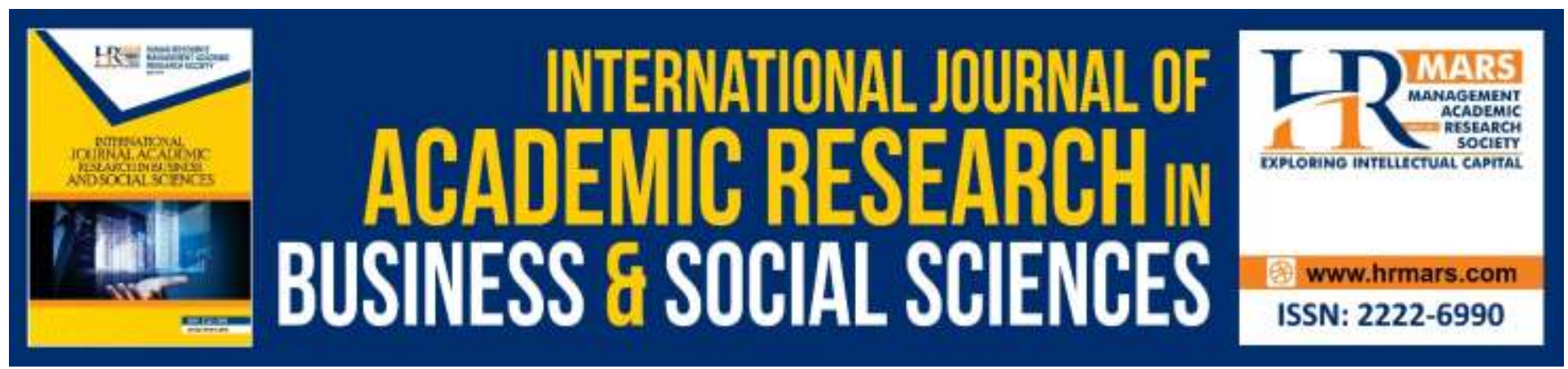

\title{
Perceptions of Social Media Use and Family values in the Northern Region of Ghana
}

\author{
Iliasu Adam \\ Kulliyyah of Islamic Revealed Knowledge and Human Sciences, International Islamic University \\ Malaysia \\ Email: adam_iliasu@yahoo.com
}

\begin{abstract}
Social media is fast replacing the traditional methods of communication and shaping how people (including family members) interact in the Ghanaian society where the use of smartphone has reached critical mass. The study employed Focus Group Discussions to explore the influence of social media use on family values in Northern region of Ghana where social media is perceived to be threatening family values and social relations of family members. A total of 47 participants took part in focus group discussions from which this paper on perception of social media use is carved out. The respondents were categorised as family heads, mothers and Generation $Y$ (youth). Six focus group discussions were held with two group discussions for each category (family heads, mothers and Generation Y). Based on the thematic analysis, 12 themes (including perception of social media use) were extracted from the focus group discussions. The findings indicate that the use of social media in family communication has the attributes of rich media. The study also showed social media is a double-edged sword and can be used for good or bad purpose. It was also revealed that that though the uses of social media have reduced visits among family members, it has not negatively affected their family values.
\end{abstract}

Keywords: Social Media, Communication, Family Values, Generation, Cohesion, Perception

\section{Introduction}

The use of social media has become a daily routine and for many people, it is indispensable. In fact, social media usage is prevalent in all spheres of life. One very important area is the family contact as social media is rapidly becoming a medium for family members to interact with one another. Factors such as geographical distance, convenience, immediacy and instantaneous communication are among the reasons why social media is becoming commonplace for family interaction (Sawyer \& Chen, 2012; Slevin, 2002). But Hampton, Sessions, Her, and Rainie (2009) cautioned that the importance of physical proximity in building and maintaining the network of family ties is being reduced by the reliance on social media. 
In 2016, the projected population of Ghana was estimated at $28,308,301$ according to Ghana Statistical Service (2016) as against the actual population of 24,658,823 in the 2010 Population and Housing Census (Ghana Statistical Service, 2012). At the end of the second quarter of 2016, the total number of mobile phone subscribers was 36,613,987 (National Communication Authority, 2016). These statistics indicate that Ghana has reached the critical mass in the use of smartphone and social media. Williams, Strover and Grant (1994) identify two different sets of critical mass concerns in mass communication technologies which are the provision of the technology and the adoption of the technology in which, Ghana has achieved both.

Despite social media being widely viewed as a positive development, people end up using the technology arguably for purposes very divergent from their intended objectives (Castells, Fernandez-Ardevol, Qiu \& Sey, 2007; Abdullahi, Rouyan, Noor \& Halim2018).

According to Kennedy, Smith, Wells, and Wellman (2008), social media leads family members to engage in online communication, at the expense of the traditional methods of communication which included face-to-face contact and meetings. Some have argued that the social media is contributing to the diminishing of the traditional family interactions and it is influencing families toward "a nomadic existence" (Slevin, 2002, p. 67) as they often communicate on the social network platforms such as Facebook, Twitter and Whatsapp, instead of physical interaction.

In the opinion of Matook and Butler (2015), the integration of these new communication technologies into family life and society is influencing social interactions between family members. They also argue that these new communication technologies have changed the landscape of communication dynamics among family members. Social media with its diverse collection and integration of technologies and applications are allowing individuals to exchange digital artefacts with one another. These basic attributes of social media can be appropriated to support various types of relationships.

\section{Problem Statement}

Prior to the proliferation of mobile phones and social media, family members regularly met face-to-face, had procedures of communicating different types of information to the family members and were physically involved in family activities. But Dunu and Ugbo (2017) observed that the emergence of these new communication technologies have brought about a significant shift in family patterns of communication. Also, Keller (2013) contends that there has been a shift in the way people communicate among themselves, "instead of face-to-face interaction, we are tending to prefer mediated communication" (p. 10). Similarly, Subramanian (2017) argues that social media has created a situation whereby people are getting used to avoiding face-to-face interaction by switching over to social media and thus reducing physical interaction of people.

Ghana represents a collective culture (Hofstede, 2011) with a hierarchical traditional setup (Nukunya, 2016; Hofstede, 2011; Gyekye, 2003; Twumasi, 1983) and laid down channels of communication (Twumasi, 1983). According to Gyekye (2003), not all types of information are disseminated to all family members. Information, he said, was given out on the need to know. For instance, a family elder who wanted to pass a particular type of information to another elder 
of the family will not pass that information through a third party. He will rather send for the intended recipient of the information to come personally and receive that information (Gyekye, 2003). The family would also decide who should be informed and how. According to Ateng, Abazaamib, and Musah (2018); Ohaka, Ogaluzor, (2018) Ghanaians are more indirect in communication. They are conscious about how to relay good or bad information. Culture-specific to Ghanaian society, Ateng, Abazaamib, and Musah (2018) stress that Ghanaians prefer conveying such information by using proverbs and analogies.

There are generational gaps in appreciating certain traditional practices. For instance, informing family members of the passing of a relative through physical visits rather than through the convenience of social media may have different value interpretations across generations. This may also speak to a form of digital divide based on value systems between the youth and the older generation. The resulting cultural practices around social media use within family life are what Williams (1977) describes as "emerging culture" as against dominant culture and residual culture. "By 'emergent' I mean, first, that new meanings and values, new practices, new relationships and kinds of relationship are continually being created" (Williams, 1977, p. 123).

Based on the above discussions, it was possible to identify three-fold problems that serve as a starting point for this study. As it has been noted above, one problem area is the possible trend of the reliance on social media in communication between family members instead of faceto-face. The second problem area involves better appreciation of how social media impacts on the relationship between family members. The third problem concerns on the validity of social media as rich media in communicating with family members.

\section{Significance of the Study}

Studying Perceptions of Social Media Use and Family values in the Northern Region of Ghana is important for two reasons. Firstly, it will help elucidate the emerging hybrid cultural practices and value systems within family life in the Northern Region of Ghana that are occasioned largely by the use of social media. Secondly, hopefully the findings from this study will help enhance the level of awareness on the effects of social media use on family values and provide ways on how to maintain healthy boundaries between its use and family relationship. Such perspective will contribute to the literature on family life within the context of modernization and development. Currently, there is no study of this kind and this study hopes to help provide perspectives on new communication technologies and their impact on family culture in Ghana. A study on the cultural dimensions of ICT using the family unit as a locus of analysis will be very valuable in informing the work of policymakers, development practitioners, educators and African communication scholars by contributing towards better understanding of new media technologies and the influence they are having on social interaction within family members.

The main objective of this study is to examine the perceptions of the use of social media to communicate among family members.

\section{Method}

The study employed qualitative research design Focus Group Discussions. Samples were recruited from among the residents in Tamale, the capital of Ghana's Northern region and two 
rural communities (Dalun in the Kumbungu district and Karaga in the Karaga district). The study was limited to three districts of the Northern region out of the 14 metropolitan, municipal and districts in in the region.

The composition of a focus group depends on the topic to be discussed and the cultural settings of the community (Merriam, 2009; Alamassi et al., 2015). Therefore, in this study, three categories of focus groups were formed in each of the three communities according to status, age and gender to find out why and how they use social media to communicate among family members. The first group is for women (above 35 years of age), the second one is for the Generation Y (people born during the 1980s and early 1990s), and the third group is for the family heads. The family head is usually the eldest male in the family and revered by other family members. The discussion continued for those categories to the point of saturation until no new information emanated from the focus group discussions. Purposeful sampling was used to choose the participants. This was to ensure that the people participating are abreast of social media use.

A total of 47 participants took part in the six focus group discussions. They included 27 males and 20 females. There were also 20 participants in the discussions who are below 30 years; 10 participants between 31 - 50 years of age and 17 participants above 50 years of age. The breakdown of the age and gender distribution is stated below.

Table 3.3 Age and gender distribution of participants in the focus group discussion

\begin{tabular}{lccc}
\hline & Male & Female & Total \\
\hline 30 years and below & 12 & 8 & 20 \\
\hline $31-50$ years & 4 & 6 & 10 \\
\hline Above 50 years & 11 & 6 & 17 \\
\hline Total & 27 & 20 & 47 \\
\hline
\end{tabular}

\section{Result}

Issues with social media abuse thematically deduced from the discourse of perception of social media use varied from fraudulent activities, engagement in illicit activities, indecent posts to betrayal of trust. Based on the discourses held to address participants' perceptions of social media use, a number of salient themes emerged which were; communication facilitation, traditional culture abrasion, and social media abuse. The subsequent paragraphs deliberately discuss each theme.

\section{Communication Facilitation}

The theme on "communication facilitation" links to five codes, namely to compensate distance, immediacy (fast information exchange, feedback) affordability, synchronicity and confidentiality are discussed in this section.

The respondents agreed that the use of social media in maintaining family values have both positive and negative effects. There was a general belief that social media's advantages outweigh their disadvantages. "I have ever heard something that social media is a like a knife. It depends on how you use it" (Participant Mahama, 23, FGD6). 
In the past, families or community members used to beat the gong gong (talking drums) to gather people to deliver a message, but with the advent of social media, such information can be limited to only the intended recipients who will receive the information at the same time. $A$ 53-year-old male in FGD4, Nash, explains:

Whether outdooring, wedding or funeral, you can just pass it within the shortest time and people can get the information and response to your request (Nash).

Espousing the use of social media, a 49-year-old participant, Simli in FGD4 explained that when family members are hooked on the same social media platform, one does not need to travel to each person to deliver the same message. Everyone will have access to the same message if it is put on the family social media platform. The message will ultimately get to the intended person even if that person is not connected to the social media platform at the time one was making the contact. Social media is a better way of ensuring that the message is delivered. But with face-to-face, one can go to the person's house and there was likelihood that you will not meet that person. The respondents agreed that it is a means of communication that cost less compared to face-to-face and telephone. The cost of data to connect to the internet is lower than the cost of making a phone call or travelling to a relative to deliver a message. There was consensus that social media was faster for both sending and receiving feedback because it does not involved travelling to the recipients of the information.

It is not expensive. You don't go to pay for an announcement to be made. The data that you are going to use is less costly, and then you will get quick response from the members. So, that is why I think social media are good, that is, less expensive and you will also get quick response (Participant Nash, FGD4).

In corroboration, participant Simli, 49, in FGD4 also shared with/told the researcher:

I think it is best because it is much easier to disseminate information on the social media than doing it orally or doing it through phone calls. The quickness that characterises the responses alone is motivating. And most times again, the cost is too is little, a bit much lesser as compared to the other mediums that one could use (Participant Simli).

Some of the participants described situations when their fathers or mothers send them to faraway communities just to call a relative or deliver a simple message. However, the proliferations of smartphone and social media networks have made communication easier. Some of the participants explained that they do not need to incur transport cost to travel to another place just to deliver a simple message. The point was stressed by Mahama, a 25-year-old male respondent in FGD6. He explains;

Social media has made communication faster, easier and cheaper. For instance, if there is information going around and you want it to get to the public faster, you can put it on social media so a lot of people will benefit from it instead of going to them one by one (Participant Mahama). 
A 55-year-old family head respondent in FGD4, Alasan, described social media as the best means of communication with other family members because;

It is quick and less costly in the sense that it reduces movement and also it makes the recipient to get the same information (Participant Alasan).

In the view of another family head respondent, a 56-year-old family head, Sumani in FGD3 said that social media has bridged the distance between family members. Social media has enabled them to be abreast of current issues.

These are very good media of communication, because, if a family member is far away from home, through this medium, you can communicate and enquire about his condition. This, you can determine if the person is healthy or not. Another benefit of it is that, current issues that are trending can be seen and heard (Participant Sumani).

On family meetings, Madam Taaya, 58 in FGD2 was of the view that;

Today, if there is any family gathering where you can't be present, once you are on social media, all you need is to get connected and you will be with the gathering from beginning to the end (Participant Taaya).

In the opinion of another 40-year-old female respondent, Adiza in FGD5, social media promotes dating between boys and girls. Sometimes a person does not have the confidence to openly tell the opposite sex of his or her intention to enter into a relationship. They can use social media to initiate the contacts and intentions. She explains that;

Sometimes some men are shy to go with a lady into her house, especially if she is still living with her family. Though, the man has the intention to marry the girl, he will prefer contacting her through social media to going directly to her house. When the intention of their relationship is made known to both families it paves the way for the man to start visiting the girl in her house (Participant Adiza).

Another reason why the participants think that social media facilitates communication was that it minimises distortion of information. They think that there was the likelihood of distortion if the same message is supposed to be given orally to several people. According to Participant Jacob, 48, in FGD4, communicating through social media ensures that all the recipients receive the same message simultaneously. The messenger cannot be accused of favouritism in terms of who gets the message first. Unlike verbal messages, you can be accused of favouring one family member over the other in the delivery of messages. A male respondent 
in FGD4, Alasan, 55, said it was difficult to verbally deliver the same message to different people at different places;

The same verbal message sent to different people may be received differently by the recipients. But if the message is documented, either written or recorded audio or video and circulated through social media, all the recipients will receive the same message at the same time. The timing of sending and receiving information is very important (Participant Alasan).

Apart from using the social media for family communication, it has become a source of news from all over the country and the world. The respondents considered social media as a dependable and reliable source of breaking news in the country as Sandow, 55 in FGD4 explained;

We get to know of what is happening in different parts of the country and the world on social media before it is broadcasted on radio or television (Sandow, 55 FGD4).

Some of the respondents said there were certain items one cannot describe with words and the only way you can communicate effectively was through pictures or videos. Adiza, a 45year-old respondent in FGD5 gave the example of clothing and fashion. She explained that when a female family member is about get married, the groom-to-be has to buy some clothing for the bride-to-be as part of the bride price;

If the girl is in the village and wants a particular type of cloth, she has to take the picture and WhatsApp it to the man who is in the city to buy them for her (Participant Adiza,).

In addition to what Adiza said, Zenabu 46, from the same group said that when a family member is getting married, the women from both families wear the same fabric on the wedding day to signify the relationship. She said the type of fabric is circulated for several weeks on the family social media platform to enable the family members to know the type of material they are to buy and sew and wear on the wedding day.

\section{Entertainment}

In the FGDs, it was the Generation Y participants who use the social media to be abreast of entertainment especially sports and music. It emerged that the male participants were more interested in sports whilst the female participant were interested in films and music. A male participant from FGD1, Damba, 25, said his colleagues in the education institution are abreast of the European soccer leagues through social media and that some of them can mention the names of the players of the team they support by rote. He said supporters of the various soccer teams tease each other on social media just for fun; 
INTERNATIONAL JOURNAL OF ACADEMIC RESEARCH IN BUSINESS AND SOCIAL SCIENCES

Vol. 10, No. 1, Jan, 2020, E-ISSN: 2222-6990 (C) 2020 HRMARS

I support Manchester United Football Club in the English Premier league and I can mention the names of the Manchester United players and their positions before the start of a particular football match. I get all this information from the social media (Damba)

Supporting the claim of Damba, Abu, 22, also of FGD1 said through social media, he knows the standings of all the 20 English premier league clubs on the league table at any particular time.

Tafa, 23, in FGD6 said he uses the social media to follow the performance of Ghanaian soccer players plying their trade abroad;

I get to know the Ghanaian players who feature for their clubs in a particular match and their performance in those matches. Through that I can predict the Ghanaian players who can make it to the national team (Tafa, 23).

Mbo, a 25-year-old female participant in FGD1 said she was abreast of the music industry in Europe and the United States of America and explained that;

I follow the weekly music charts in Europe and United States on social media and I can mention the names of the musicians and the titles of their songs that are trending in a particular week (Participant Mbo).

Corroborating Mbo's claim, a female respondent in FGD6, Awabu, 20, said she follows the music chart on Youtube and Facebook and that she was able to tell the number of views and likes of certain musicians on those social network sites.

Budaali, 25-year-old male participant in FGD6 claimed that he downloads the latest films and music from the Internet and shares with his colleagues. He declined to disclose how he downloads the blockbusters.

Another area where the respondents use social media for entertainment was for playing on-line games with unknown competitors. The most popular game among the Generation $Y$ participants was scrabble. Participant Suglo, in FGD1 explains when and how he plays online scrabble;

When I am bored and I have enough data on my phone, I go online to look for a competitor who is willing to play (Suglo).

\section{Traditional Culture Abrasion}

They were also of the view that social media is contributing towards the weakening of their culture. As described by a 55-year-old female respondent, Gulba in FGD2: 
Social media contributes towards the weakening of the foundation of the family because family issues that are being discussed on social media are no more secrets and these should have been within the family (Participant Gulba)

Not everything about a family should be in the public domain. According to participant Fueseini, the openness and easy access to information associated with social media should not have been so. "There should have been some amount of mystery and fear in the society. But social media is demystifying some of our beliefs" (Participant Fuseini, 58, from FGD3).

Expressing her reservation about the use of social media, 55-year-old Madam Gulba said though the usage of social media is good, but one negative issue about social media is that "our culture is threatened" and it is also "used for gossip and this goes a long way to damage someone in the society" (Participant Gulba).

The announcement of the death of a family member on social media platforms undermines the culture and tradition of the people. Explaining why it undermines their culture, 60-year-old Dawuni in FGD3, who is a sub-chief in Dalun;

It is a taboo to announce fresh death of a family member. In the olden days, a corpse could be in the room for a day or two awaiting the arrival of a family member before burial. Culturally, this person will come with some items like, a goat, fowl, and other items. But these days, they will say once the person is dead, there is no need to waste time; all they have to do is prepare the corpse for burial. So it is not good (Participant Dawuni).

Marriage is the union between two families and due processes have to be followed before and during the marriage. According to 47-year-old Madam Wunam from FGD2, if a problem arises in the marriage that is leading to divorce, the same process must be followed in dissolving the marriage instead of announcing it on social media;

Customarily, when you are to marry, the elders will advise you to accept and take care of the lady for the sake of the following people, the aunty, father, mother, uncle etc. so it's not good to post problems of the marriage on social media without consulting these people (Participant Wunam).

Explaining further, 60-year-old Madam Azara in FGD2 said the use of social media was not part of their traditional medium of communication and described it as "something that pleases the legs but not the heart because not everything can be discussed on social media." It means that, though the message has been delivered, it was the desire to have physical interaction that matters most. "Instead of paying "face-to-face visits to family members and friends to see and feel their presence, most of us resort to social media and this is against our culture" (Participant Azara). 
A 25-year-old respondent, Damba, from FGD1 said, even though social media has helped in family communication, it was gradually replacing visitation. Family members in the same neighbourhood use social media to communicate with each other instead of physical interaction. He advised that;

people should not always rely mainly on social media for communication; its good we go face to face and visit each other or else we lose touch of our homes because we are always on social media without physical visitation (Participant Damba)

Though social media promotes family interaction, Participant Sheini from FGD3 said it was not all the family members who have access to phone and/or social media. Therefore, the over reliance on social media as a medium of communication will leave some family members out.

According to another respondent in FGD4, 55-year-old Sandow was of the view that the only thing that strengthens family ties is the phone and not social media. "Face-to-face interactions are good and this brings about family unity."

\section{Social Media Abuse}

According to Participant Danaa, 50-year-old male participant in FGD4, some people use the social media to betray the family by revealing family secrets. He explained that;

Sometimes, we want something to be confidential, but people can decide to leak it out to the public when you want it to be within the family setup (Participant Danaa).

A female respondent in FGD1, Lala, said many people have become victims of fraud and scam through the use of the social media.

A 20-year-old male respondent in FGD1, Azima accused some people of not being truthful on social media. "They will tell you that they are in Tamale whilst they are in Dalun".

Some of the respondents are of the notion that the use of social media promotes illicit relationships especially amongst teens. The young men will stand outside and call the young ladies via the phone or social media without the knowledge of the parents. Shetu, 48, from FGD5 bemoans the sue of social media for such acts and said;

Another bad aspect of it is that, our young girls are being misled by the use of the phone. The young men will stand outside and call them via the phone without the knowledge of the parent. In the olden days, these things were not there, and so that is why these days they divorce them through the phone and social media (Participant Shetu). 
A female respondent, Balma, 55, recounted how courtship was previously done. She said the man had to visit his future in-laws severally before making his intentions known to the girl's family. The girl's family will then decide whether to give their daughter out for the marriage;

But these days, a girl will even give birth to three or four children and you the parents do not even know the man or men responsible (Participant Balma).

Sixty-year-old participant Dawuni from FGD3 said he had caused to blame a family member for forwarding a video of a girl who was caught shoplifting. She was stripped naked and pepper was put into her private part. He described the scene as "very bad and a disgrace to womanhood."

The distribution of gory pictures of accident scenes on social media can affect the emotions of the immediate family members of the victims. According to respondent Nash, information about any accident can be published on social media without the gruesome pictures.

Participant Neindow, 24, in FGD6 described it as pathetic to find people concentrating on taking pictures at an accident scene instead of helping the victims. Recounting his experience at an accident scene, participant Bisung, 22 in FGD6 said he witnessed an accident on the campus of the Tamale Technical University when a motor rider knocked down a pedestrian. Instead of the rider who was not hurt attending the victim, he brought out his cell phone and started taking pictures of the victim and the motorbike.

The discourse on RQ3 revealed that the respondents had both positive and negative perception of social media use in family communication. The advantages are that it compensates for distance, synchronised information is shared among family members, it is affordable, the information and feedback are immediate and interaction among family members is high. The disadvantages according the respondents are that it is open to abuse and misuse and it discourages people from physical interactions.

\section{Discussion}

In rural northern Ghana, there were no telephones and people used to communicate through writing letters or extending verbal messages through a third party to family members who live far away from each other. However, the advent of social media has eased communication between family members irrespective of where they live. Rosenthal (2008) helps make this distinction by observing that newsletters by e-mail are still newsletters, but blogs bring personalized and interpersonal communication into the public domain. Social media use in family communication is perceived to be cheaper, easier, faster, timelier and more immediate in terms of receiving feedback. According to recent study, social media is a mechanism that allows users to communicate with thousands of individuals all over the world thus starts within the family (Williams et al., 2012). It is clear from the field that the majority of the people in the area use social media to connect and keep in touch with family and friends, interact with people they 
seldom see, chat with old friends and make new friends. As indicated, information can be disseminated simultaneously among family members without distortions. Quite apart, its use also compensates for the distance a family member would have travelled just to deliver a simple message. Social media platforms like the Facebook, Flickr, YouTube, Linkedln, Twitter, and numerous others are inexpensive and completely free to use for the purpose of communication (Whiting, \& Williams, 2013). O'Keeffe and Clarke-Pearson (2011) posits that social media is used by adolescent and family members to connect with one another on homework, assignment and group projects. These allow adolescents from the same family to gather outside of classroom to collaborate and exchange ideas about school assignments.

Social media as a portal for entertainment and communication has grown exponentially in recent years. These social media network sites serve as a one-stop shop for various types of entertainment. The study revealed that some of the people in the area use social media for watching and discussing sports, listening and sharing music, watching and sharing movies/films. Entertainment in this theme relates to jokes, films, music and social games played on Social Network Sites. According to Khoo, Merritt and Cheok (2008), it is a ppositive sign that family members including the older members are participating in the usage of the social media. This brings more benefits considering the active interaction with the younger family members through these social media activities like discussion of sports or sharing music and movies. They indicated that this could strengthen family bonding and bring the youth closer to the culture of the people in the area. This section reports the respondents' perception of the use of social media for entertainment. Social media use in Ghana has demonstrated to be a sound entertainment platform since it is awash with jokes and several varieties of music and films. These range from text messages, photos, audio and audio-visual jokes. There are some family members who post entertainment information on family social media platforms thereby making entertainment one of the favourite uses of social media by family members. In corroboration, Whiting and Williams (2013) found social interaction, information seeking, pass time, entertainment, relaxation, communicatory utility, convenience utility, expression of opinion, information sharing, and surveillance/knowledge about others as some of the uses of the social media by the majority of people including family members.

The use of social media may result in varied changes or differences in social and cultural interaction among the people in the Northern region of Ghana. It is revealed that traditional culture abrasion relates to insolence and discreet family information. This study found the effects of perception of the use of social media on traditional culture in the northern region of Ghana. The modern technology is perceived as not fit with cultural practices of the people in the area as such heads of families tends to caution some members on the use or impose sanctions on those who abuse it. For instance, using the social media to communicate false, humiliating, or hostile information about other people is the most common risk family members' surfer. Though culture is inseparable from people and it is cherished and relished, the over dependence on the social media use is challenging the adherence to some core values of families. The respondents admit that social media helps to strengthen family relationship, friendship and happiness. The use of social media has discouraged or reduced family members from visiting each other which a respondent described as an important aspect of family values. As pointed out in the discussions, 
the perception is that the use of social media in family communication threatens the fabric of their tradition and cultures which includes visitation, physical interaction, respect and adherence to family values. Subramanian (2010) cautioned that users ought to be cognizant of social and cultural norms and fashion in a manner not to betray and wander from what might be expected. The study found that the use of social media in family communication promotes insolence especially among the youth communicating on social media. According to O'Keeffe and ClarkePearson (2011), social media becomes a risk to adolescents in categories like peer-to-peer, viewing inappropriate content and lack of understanding of online privacy issues. As revealed, most of the participants expressed worry that family secrets are likely to be revealed easily by family members on social media. Kral (2011) argues that social media should instead be used as channels to express thoughts, cultural activities and concerns of the communities.

Social media users have the chance to connect with relatives and friends and as well form or create sense of belonging to a group that share similar interests. Social media has become easy family platforms used to foster relationships and interactions, but at the same time its misuse or abuse can cause conflicts in these relationships. Lumby (2010) is also of the opinion that the use of social media as a means of social interaction is an intriguing development thus becoming a typical activity. For instance, social media is among the popular self-representational tools for people to communicate, build, display and perform their identity (Carlson, 2013). Another worrying reservation of the use of social media raised during the focus group discussions was its use to swindle people. Social media also provides other features that are attractive to criminals. These scammers posing as one of your acquaintance would get you to part with some money because they are in a dire situation. The social media is also perceived as fueling tensions which creates rivalry among family members and leads to blood feuds. The fact that individuals have the freedom to reveal as much or as little as they want to on social media make some people lie. Some people will lie about their lives, which is often an effort to portray a false impression of themselves on social media. Others will deliberately mislead one as to his or her whereabouts. Also, the circulation of indecent pictures such as pornography and picture of victims of accident and the accident scenes were also described as abuse of the social media use. While some families call for a ban on its members' usage of social media, some suggested elaborate education of members to better understand how damaging social media could be.

\section{Conclusion}

Social media has redefined who people relate, interact and communicate with. The use of social media in family communication has brought family members closer than before and families with social network platforms to be in constant contact with each other irrespective of location. Social media has blurred the time, distance, age and gender barriers in communicating among family members. Social media has reconnected and established relationships between family members who hitherto did not know each other or have lost contact with each other. It is encouraging dialogue and information flow between family members irrespective of age or gender.

In support of the sudden change in the traditional mode of communication, Williams' (1977) conceptualization of cultures as process of social change that consists of a set of relations between dominant, residual and emergent features infers that there cannot be a radical 
departure from dominant to emergent cultures. He therefore referred to the elements in emergent cultures as the new meanings and values, new practices, new relationships and kinds of relationships that are continually being created. On emerging culture, Turkle (2011) found that the proliferation of mobile phone for that matter, Whatsapp platform has reduced the quality and intimacy of face-to-face relationships.

These concepts can be applied to the current state of social media and family values in the northern region of Ghana. The use of the talking drums as medium of communication that was once dominant in cultures in the northern region has become peripheral and irrelevant, though talking drums have not disappeared. A social media use is gradually rendering that such medium of communication is unimportant and peripheral in sharing information with community or family members. Social media is a classic example of what Williams (1977) described as oppositional emergent culture in communication. The use of social media is an emergent culture in family communication and is replacing some elements of the previous dominant or traditional method of communication such as the use of talking drums. Social media is now commonly used to deliver harmless messages such as the news of a new born baby to other family instead of sending emissaries on long journeys just to deliver that message. The interactions of the family with other members and transmission of messages via any media platform are routed through social institutions which control the production and consumption of culture (Murthy, 2012).

\section{Competing Interests}

It is declared that there is no competing interest.

\section{Funding}

This research was solely author-funded

\section{Availability of Data and Materials}

To ensure confidentiality, and for the fact that information about families is sensitive, the raw data would not be deposited in publicly available repositories. It is available and can be accessed on request.

\section{Consent for Publication}

Consent for publishing this article was sought from the participants involved, which was stated in the informed consent form during the data collection. They agreed and signed/thumb-printed before they took part in the interviews and answering the questionnaire.

\section{Ethical Approval and Consent to Participate}

The study was subjected to thorough ethical examination by experienced professors in the field in the Kulliyyah (Faculty) of Islamic Revealed Knowledge and Human Sciences, International Islamic University Malaysia. Permission was also granted by the participants to carry out the research on them. Both written and verbal informed consent were obtained from the study participants by assuring them of anonymity and confidentiality, and informing them about the purpose of the research. 
INTERNATIONAL JOURNAL OF ACADEMIC RESEARCH IN BUSINESS AND SOCIAL SCIENCES

Vol. 10, No. 1, Jan, 2020, E-ISSN: 2222-6990 ๔ 2020 HRMARS

\section{References}

Abdullahi, A., Rouyan, N. B. M., Noor, S. S. Binti M., \& Halim, Z. Bin A. (2018). Sentence Construction Errors among Malay Arabic Learners at Universiti Sultan Zainal Abidin. International Journal of Academic Research in Business and Social Sciences, 8(6), 953966.

Adam, I. (2020). Perceptions of Social Media Use and Family values in the Northern Region of Ghana. International Journal of Academic Research in Business and Social Sciences, 10(1), 209-226.

Alamassi, S. M. S., Al Jneibi, F. S., Al Kaabi, F., Recio, D. C. H., El Zaatari, W., \& Panitsides, E. A. (2015). WHAT HINDERS EDUCATIONAL CHANGE? SCHOOL PRINCIPALS' PERSPECTIVES IN THE UAE CONTEXT. Multilingual Academic Journal of Education and Social Sciences, 3(1), $52-74$.

Almalki, S. (2016). Integrating quantitative and qualitative data in mixed methods research challenges and benefits. Journal of Education and Learning, Vol. 5(3), 288-296. doi:10.5539/jel.v5n3p288

Ateng, M. A., Abazaamib, J., \& Musah, A. A. (2018). Exploring the role of culture in shaping the Dagbon ethnopolitical peace negotiation processes. International Negotiation, 23, 515536. doi:10.1163/15718069-23031164

Carlson, B. (2013). The 'new frontier': Emergent Indigenous identities and social media. In M. Harris, \& M. Nakata, The Politics of Identity: Emerging Indigeneity (pp. 147-168). Sydney: University of Technology Sydney E-Press.

Castells, M., Fernandez-Ardevol, M., Qiu, J. L., \& Sey, A. (2007). Mobile communication and society. A global perspective. Cambridge: Massachusetts Institute of Technology.

Creswell, J. W., Clark, V. L., Gutmann, M. L., \& Hanson, W. E. (2010). An expanded typology for classifying mixed methods research into designs. In A. Tashakkori, \& C. Teddlie, Handbook of mixed methods in social and behavioral research (pp. 159-196). Thousand Oaks: SAGE.

Dunu, I. V., \& Ugbo, G. O. (2017). Separated household? Effects of personalized communication devices on Nigerian families' communication pattern. New Media and Mass Communication, 60, 28-40. Retrieved from https://www.researchgate.net/profile/Kalpathy_Subramanian/publication/319422885_I nfluence_of_Social_Media_in_Interpersonal_Communication/links/59a96d950f7e9b279 0120fea/Influence-of-Social-Media-in-Interpersonal-Communication.pdf

Ghana Statistical Service. (2012). 2010 population and house census final results. Accra: Ghana Statistical Service. Retrieved from http://www.statsghana.gov.gh/docfiles/2010phc/2010_POPULATION_AND_HOUSING_C ENSUS_FINAL_RESULTS.pdf

Ghana Statistical Service. (2016). Population statistics. Accra: Ghana Statistical Service. Retrieved from http://www.statsghana.gov.gh/pop_stats.html Gyekye, K. (2003). African cultural values: An introduction. Accra: Sankofa Publishing Company. Hampton, K. N., Sessions, L. F., Her, E. J., \& Rainie, L. (2009). Social isolation and new technology. Philadelphia: Pew Internet and America Life Project. 
Hofstede, G. (2011). Dimensionalizing cultures: The Hofstede model in context. Online Reading in Psychology and Culture, Vol. 2(1), 1-26. doi:10.9707/2307-0919.1014

Keller, M. (2013 ). Social Media and Interpersonal Communication. Social Work Today, 13(3), p. 10. Retrieved from https://www.socialworktoday.com/archive/051313p10.shtml

Kennedy, M. S., Ferrell, L. K., \& LeClair, D. T. (2001). Consumers' trust of salesperson and manufacturer: an empirical study. Journal of Business Research, 51(1), 73-86. doi:0.1016/S0148-2963(99)00039-9

Kennedy, T. L., Smith, A., Wells, A. T., \& Wellman, B. (2008). Networked families. Washington DC: PEW Internet and American Life Project. Retrieved July 1, 2017, from http://www.pewinternet.org

Khoo, E. T., Merritt, T., \& Cheok, A. D. (2009). Designing physical and social intergenerational family entertainment. Interacting with Computers, 21, 76-87.

Kral, I. (2011). Youth Media as Cultural Practice: Remote Indigenous Youth Speaking Out Loud. Australian Aboriginal Studies, 1(1), 4-16.

Kumar, R. (2011). Research methodology. A step-by-step guide for beginners (3rd ed.). London: SAGE Publications Ltd.

Lumby, B. L. (2010). Cyber-Indigeneity: Urban Indigenous identity on Facebook. 'The Australian Journal of Indigenous Education, 39(Supplement), 68-75.

Matook, S., \& Butler, B. (2015). Social media and relationship. The International Encyclopedia of Digital Communication and Society, pp. 1-12. doi:DOI:

10.1002/9781118767771.wbiedcs097

Merriam, S. B. (2009). Qualitative research a guide to design and implementation. Revised and expanded from qualitative research and case study applications in education. San Francisco: Jossey-Bass.

Murthy, D. (2012). Towards a sociological understanding of social media: Theorizing Twitter. Sociology, 46(6), 1059-1073. doi:10.1177/0038038511422553

National Communication Authority. (2016, September). National Communication Authority Quarterly News. Retrieved from NCA: http://www.nca.org.gh/assets/Uploads/Quaterlystatistics-03-11-16-fin.pdf

Nukunya, G. (2016). Tradition and change in Ghana: An introduction to sociology (Revised and Expanded ed.). accra: Woeli Publishing sevices.

O'Keeffe, G. S., \& Clarke-Pearson, K. (2011, April). The Impact of Social Media on Children, Adolescents, and Families. PEDIATRICS: Official Journal of American Academy of Pediatrics., 127(4), 800-804. doi:; DOI: https://doi.org/10.1542/peds.2011-0054

Ohaka, J., Ogaluzor, O. I. (2018). Corporate Social Responsibility Accounting and the Effect of Donations on Profitability of Oil and Gas Companies in Nigeria, International Journal of Academic Research in Accounting, Finance and Management Sciences 8 (3): 265-276.

Sawyer, R., \& Chen, G.-M. (2011). The impact of new social media on intercultural adaptation. Senior Honors Projects(Paper 242). Retrieved from digitalcommons.uri.edu/srhonorsprog/242

Slevin, J. (2002). The Internet and society. Cambridge: Polity Press. 
Subramanian, K. (2017). Influence of Social Media in Interpersonal Communication. International journal of scientific progress and research (IJSPR), 38/2(109), 70-75. Retrieved January 28, 2019, from https://www.researchgate.net/profile/Kalpathy_Subramanian/publication/319422885_I nfluence_of_Social_Media_in_Interpersonal_Communication/links/59a96d950f7e9b279 0120fea/Influence-of-Social-Media-in-Interpersonal-Communication.pdf

Subramanian, M. (2012). New Modes of Communication: Web Representations and Blogs: United States: South Asians. In Encyclopedia of Women and Islamic Cultures. Brill. Retrieved from https://search.credoreference.com/content/entry/brillewica/new_modes_of_communi cation_web_representations_and_blogs_united_states_south_asians $/ 0$

Turkle, S. (2011). Alone together: Why we expect more from technology and less from each other. New York: Basic Books.

Twumasi, P. A. (1983). The changing family in the Ghanaian context. Lusaka: UNESCO Division for the of Development.

Whiting, A., \& Williams, D. (2013). Why people use social media: a uses and gratifications approach. Qualitative Market Research: An International Journal, 16 (4), 362-369. doi:0.1108/QMR-06-2013-0041

Williams, D. L., Crittenden, V. L., \& McCarty, P. (2012). The use of social media: an exploratory study of usage among digital natives. Journal of Public Affairs, 12(2), 127-136. doi:DOI: 10.1002/pa.1414

Williams, F., Strover, S., \& Grant, A. E. (1994). Social Aspects of New Media Technologies. In J. Bryant, \& D. Zillmann, Media effects: Advances in theory and research (pp. 437-462). Hillsdale: Lawrence Erlbaum Associates.

Williams, R. ( 1977). Marxism and literature. Kuala Lumpur: Oxford University Press 